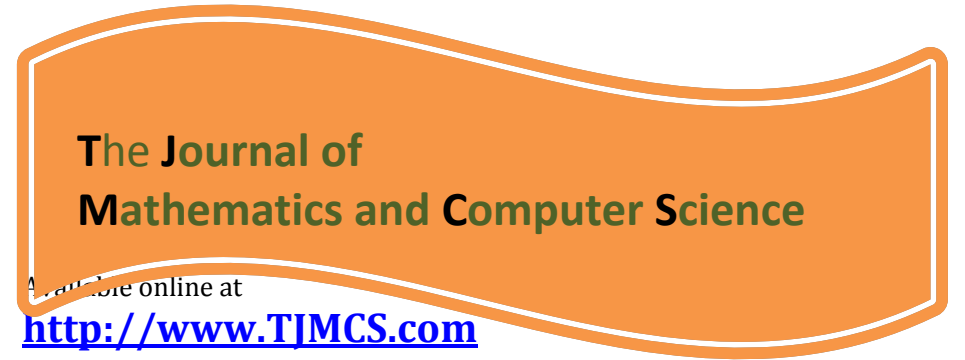

The Journal of Mathematics and Computer Science Vol. 4 No.3 (2012) 418 - 427

\title{
Investigation of the Dynamic Behavior of Periodic Systems with Newton Harmonic Balance Method
}

\author{
M. Mashinchi Joubari ${ }^{1}$, R. Asghari ${ }^{2}$, M. Zareian Jahromy ${ }^{3}$ \\ ${ }^{1}$ Department of Mechanical Engineering, Babol University of Technology, Babol, Iran \\ mmmjouybari@gmail.com \\ ${ }^{2}$ Applied Mathematics Department, Mathematics Science Faculty, Guilan University, Rasht, Iran \\ meisam.mathhome@gmail.com \\ ${ }^{3}$ Department of Mechanical Engineering, Hormozgan University, Bandar Abbas, Iran \\ M_Z_dj_1366@yahoo.com
}

Received: February 2012, Revised: May 2012

Online Publication: July 2012

\begin{abstract}
In this paper, Newton Harmonic Balancing Method (NHBM) is applied to scrutinize free vibration analysis of the nonlinear oscillatory systems. This method is combined by the Harmonic Balance and Newton's methods. Two classical cases are used to illustrate the applicable of NHBM and results compared by other analytical methods and ODE solver built in MATLAB. The results of the NHBM are shown that the solution quickly convergent and does not need to complicated calculations. So it is applied for various problems in engineering specially vibration equations.
\end{abstract}

\section{Keyword}

Newton Harmonic Balance Method, Nonlinear vibration, Oscillatory system, high accuracy

\section{Introduction}

Nonlinear oscillations are important issue in physical science, mechanical structures and other engineering problems. The fluctuation, stability $[1,2]$ and natural frequencies are basic items in oscillatory systems. So, investigating about the influence of various parameters of these items is important in the design step.

Mainly nonlinear vibration of oscillation systems are modeled by nonlinear differential equations. Obtaining exact solution for these nonlinear problems is difficult and time consuming, thus scientist tried to find new approaches for overcome it. Recently, many authors used various analytical methods for solving nonlinear equations in mechanical systems. Some kind of these methods like Homotopy Perturbation Method (HPM), Homotopy Analysis Method (HAM) and Variational Iteration Method (VIM) are powerful methods and can used for almost all types of nonlinear equations [3-14]. Some other methods like Frequency Amplitude Formulation (FAF), Max-Min Approach (MMA), Energy Balance Method (EBM), Harmonic Balance Method (HBM) and Newton Harmonic Balance Method 
(NHBM) introduced for oscillation systems [15-23]. In these types of methods with obtaining the motion frequency and having the initial conditions the result achieved.

NBHM incorporates of both Newton's Method and Harmonic Balance Method. Wu et al. [21] introduced this method and applied it on three examples. Lai et al. [22] analyzed first, second and third orders analytical approximation for second order differential equation with cubic quantic nonlinearities. Also, they compared various order of obtained frequency with exact frequency.

In current research, NBHM is applied on three cases of nonlinear oscillatory systems and first and second orders approximation of this method is investigated. Results obtained by NHBM compared with ODE solver built in MATLAB. Also, the influence of the initial amplitude studied on the system response and stability.

\section{Analysis, solution procedure, results and discussion of cases}

The application of Newton Harmonic Balance Method (NHBM) in mechanical structures especially oscillation systems investigated on three nonlinear vibration problems.

\section{1 case 1}

Consider the motion equation of special Duffing-harmonic oscillator as follows [18]:

$\ddot{u}+\frac{u^{3}}{1+u^{2}}=0 \quad \rightarrow \quad \ddot{u}\left(1+u^{2}\right)+u^{3}=0$

Under the transformation $\tau=\omega t$, the Eq. (1) can be written as:

$\omega^{2} u^{\prime \prime}(\tau)\left(1+u^{2}(\tau)\right)+u^{3}(\tau)=0$

Where $\omega$ is angular frequency and prime denotes differentiation with respect to $\tau$.

Also, initial condition is:

$u(0)=A \quad u^{\prime}(0)=0$

Where $A$ denotes the maximum amplitude.

With second order approximation, $u(\tau)$ and $\omega^{2}$ may be extend as follows [21, 22]:

$u(\tau)=u_{1}(\tau)+\Delta u_{1}(\tau)$

$\omega^{2}=\omega_{1}^{2}+\Delta \omega_{1}^{2}$

Substituting Eq. (4) and Eq. (5) into Eq. (3), we have:

$\left(\omega_{1}^{2}+\Delta \omega_{1}^{2}\right)\left(u_{1}^{\prime \prime}+\Delta u_{1}^{\prime \prime}\right)\left(1+\left(u_{1}+\Delta u_{1}\right)^{2}\right)+\left(u_{1}+\Delta u_{1}\right)^{3}=0$

According to initial conditions and for first order approximation, we set:

$u_{1}(\tau)=A \cos \tau, \quad \Delta u_{1}=\Delta u^{\prime \prime}=\Delta \omega_{1}^{2}=0$

With substitute Eq. (7) into Eq. (6) and avoiding the presence of secular terms, the angular frequency for first order approximation obtained and written as follows:

$-\omega_{1}^{2}+\frac{3}{4} A^{2}-\frac{3}{4} A^{2} \omega_{1}^{2}=0 \quad \Rightarrow \quad \omega_{1}=\sqrt{\frac{3 A^{2}}{4+3 A^{2}}}$

For the second analytical approximation, we set:

$\Delta u_{1}=c(\cos \tau-\cos 3 \tau)$

Substituting Eq. (9) into Eq. (6) and expanding the achieved expression in a trigonometric series and then putting the coefficients of $\cos \tau$ and $\cos 3 \tau$ equal to zero, Eq. (10) and Eq. (11) obtained.

$\left(-3 A^{3}+4 A\right) \Delta \omega_{1}^{2}+c\left(-6 A^{2}+4 \omega_{1}^{2}-2 A^{2} \omega_{1}^{2}\right)+4 A \omega_{1}^{2}-3 A^{3}+3 A^{3} \omega_{1}^{2}=0$ 


$$
A^{3} \Delta \omega_{1}^{2}+c\left(3 A^{2}-36 \omega_{1}^{2}-19 A^{2} \omega_{1}^{2}\right)+A^{3} \omega_{1}^{2}-A^{3}=0
$$

Solving Eq. (10) and Eq. (11) simultaneously, it is obtained:

$$
\begin{aligned}
& \Delta \omega_{1}^{2}=-\frac{-124 A^{2} \omega_{1}^{2}-70 A^{4} \omega_{1}^{2}+188 A^{2} \omega_{1}^{4}+55 A^{4} \omega_{1}^{4}+144 \omega_{1}^{4}+15 A^{4}}{-15 A^{4}+188 A^{2} \omega_{1}^{2}+55 A^{4} \omega_{1}^{2}-12 A^{2}+144 \omega_{1}^{2}} \\
& c=-\frac{4 A^{3}}{-15 A^{4}+188 A^{2} \omega_{1}^{2}+55 A^{4} \omega_{1}^{2}-12 A^{2}+144 \omega_{1}^{2}}
\end{aligned}
$$

From Eq. (4) and Eq. (5), and using second order analytical solution the angular frequency and the system displacement may be written as:

$$
\begin{aligned}
& \omega=\sqrt{\frac{3 A^{2}}{4+3 A^{2}}-\frac{-124 A^{2} \omega_{1}^{2}-70 A^{4} \omega_{1}^{2}+188 A^{2} \omega_{1}^{4}+55 A^{4} \omega_{1}^{4}+144 \omega_{1}^{4}+15 A^{4}}{-15 A^{4}+188 A^{2} \omega_{1}^{2}+55 A^{4} \omega_{1}^{2}-12 A^{2}+144 \omega_{1}^{2}}} \\
& u(t)=(A+c) \cos \tau-(c) \cos 3 \tau
\end{aligned}
$$

Where $c$ is evaluated from Eq. (13).

\subsection{Result and discussion of this case}

Motion equation of special Duffing-harmonic oscillator investigated and solved with NHBM. The frequency obtained by applying second order approximation of NHBM (Eq. (14)) compared with exact solution and other analytical solutions in table 1. Also, time histories of system displacement for two different initial amplitude illustrated using NHBM and time marching solution in Fig. 1. From this figure and table 1, NHBM has excellent agreement with other analytical or exact results and provides suitable approximating for this type of problems.

Fig. 2 shows the phase plane of the system which indicates displacement versus velocity and showing the system stability. In addition Fig. 3 shows the displacement behavior of the system versus time and initial amplitude.

Table1. Comparison between NHBM obtained frequency with frequencies obtained in other literatures.

\begin{tabular}{|c|c|c|c|c|c|c|}
\hline A & He [24] & $\begin{array}{c}\text { Mickens } \\
{[25]}\end{array}$ & $\begin{array}{c}\text { Tiwari et al. } \\
{[26]}\end{array}$ & $\begin{array}{c}\text { Turgut et al. } \\
{[18]}\end{array}$ & $\begin{array}{c}\text { Present study } \\
\text { Eq. (14) }\end{array}$ & $\begin{array}{c}\text { Exact } \\
\text { solution [18] }\end{array}$ \\
\hline 0.1 & 0.0863 & 0.0844 & 0.0862 & 0.0862 & 0.0844 & 0.0844 \\
\hline 1 & 0.6547 & 0.6464 & 0.6436 & 0.6516 & 0.6383 & 0.6368 \\
\hline 10 & 0.9934 & 0.9931 & 0.9910 & 0.9931 & 0.9921 & 0.9909 \\
\hline
\end{tabular}




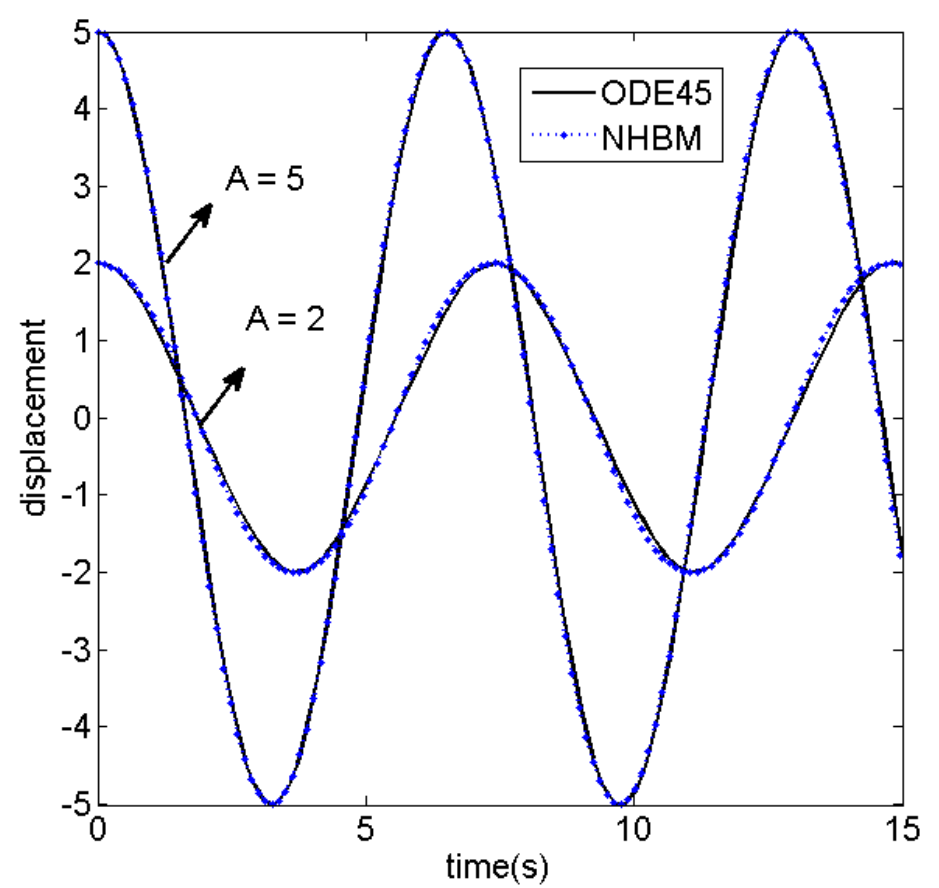

Fig. 1. System displacement for various $A$.

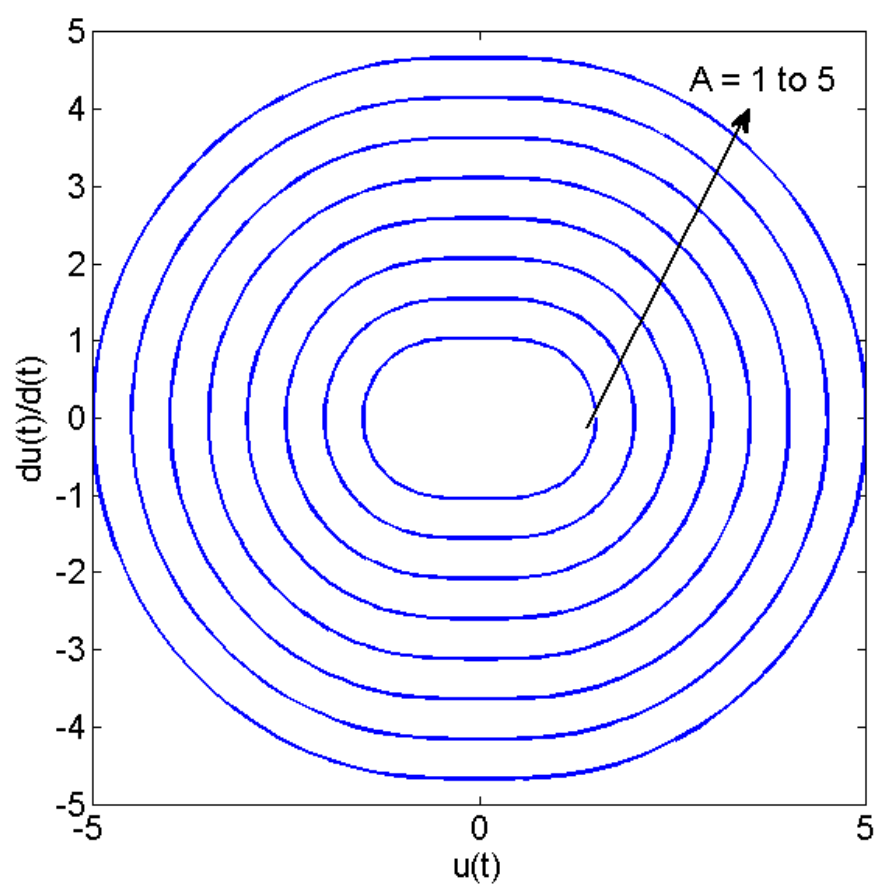

Fig. 2. Phase plan maps for showing the influence of $A$ in the system stability. 


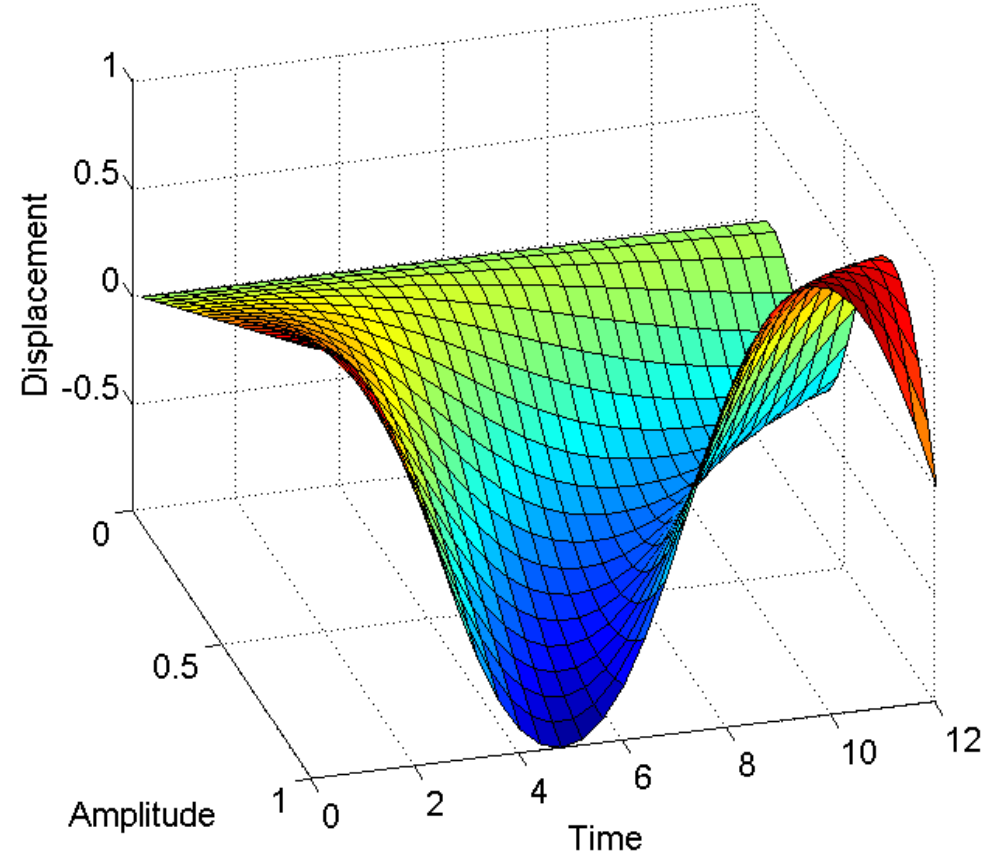

Fig. 3. Influence of initial amplitude on time histories of NHBM displacement.

\section{3 case 2}

Eq. (16) represents the mathematical pendulum without friction [23].

$\ddot{u}+\Omega^{2} \sin u=0$

Substituting $\tau=\omega t$ and suitable approximation for $\sin (u)$, Eq. (16) changes to:

$\omega^{2} u^{\prime \prime}+\Omega^{2}\left(u-\frac{u^{3}}{3}+\frac{u^{5}}{120}\right)=0$

Where initial conditions expressed as initial displacement, equal to maximum amplitude as follows:

$u(0)=A \quad u^{\prime}(0)=0$

Substituting Eq. (4) and Eq. (5) into Eq. (17), the following expression obtained.

$\left(\omega_{1}^{2}+\Delta \omega_{1}^{2}\right)\left(u_{1}^{\prime \prime}+\Delta u_{1}^{\prime \prime}\right)+\Omega^{2}\left(u_{1}+\Delta u_{1}\right)-\frac{\Omega^{2}}{6}\left(u_{1}+\Delta u_{1}\right)^{3}+\frac{\Omega^{2}}{120}\left(u_{1}+\Delta u_{1}\right)^{5}=0$

By linearizing Eq. (19) respect to $\Delta u_{1}$ and $\Delta \omega_{1}^{2}$ yield:

$\left(\omega_{1}^{2}+\Delta \omega_{1}^{2}\right) u_{1}^{\prime \prime}+\omega_{1}^{2} \Delta u_{1}^{\prime \prime}+\Omega^{2}\left(u_{1}+\Delta u_{1}\right)-\frac{\Omega^{2}}{6}\left(u_{1}^{3}+3 u_{1}^{2} \Delta u_{1}\right)+\frac{\Omega^{2}}{120}\left(u_{1}^{5}+5 u_{1}^{4} \Delta u_{1}\right)=0$

Substituting Eq. (7) into Eq. (20) for first order approximation and avoiding the presence of secular terms the angular frequency obtained as follows:

$\omega_{1}=\Omega \sqrt{\left(1-\frac{A^{2}}{8}+\frac{A^{4}}{192}\right)}$

Second order analytical approximation may be achieved by Substituting Eq. (9) into Eq. (20) and expanding the obtained expression in a trigonometric series and then putting the coefficients of $\cos \tau$ and $\cos 3 \tau$ equal to zero, results achieved in a set of simultaneous equations in terms of $\Delta \omega_{1}^{2}$ and $c$ as follows:

$(-A) \Delta \omega_{1}^{2}+c\left(-\omega_{1}^{2}+\Omega^{2}+\frac{3}{2} \Omega^{2} A^{2}+\frac{25}{16} \Omega^{2} A^{4}\right)-A \omega_{1}^{2}+\Omega^{2} A+\frac{3}{4} \Omega^{2} A^{3}+\frac{5}{8} \Omega^{2} A^{5}=0$ 
$c\left(9 \omega_{1}^{2}-\Omega^{2}-\frac{3}{4} \Omega^{2} A-\frac{5}{16} \Omega^{2} A^{4}\right)+\frac{1}{4} \Omega^{2} A^{3}+\frac{5}{16} \Omega^{2} A^{5}=0$

Solving Eq. (22) and Eq. (23) simultaneously, it is obtained:

$$
\begin{aligned}
& \Delta \omega_{1}^{2}=-\frac{3 A^{4} \Omega^{2}\left(4+5 A^{2}\right)^{2}}{16\left(128+96 A^{2}+85 A^{4}\right)} \\
& c=-\frac{4 A^{3}+5 A^{5}}{128+96 A^{2}+85 A^{4}}
\end{aligned}
$$

Second order analytical approximate frequency and system response using Eqs. (4), (5), (9), (24) and (25), can be written as:

$$
\begin{aligned}
& \omega=\sqrt{\omega_{1}^{2}+\Delta \omega_{1}^{2}}=\Omega \sqrt{\left(1-\frac{A^{2}}{8}+\frac{A^{4}}{192}\right)-\frac{3 A^{4}\left(4+5 A^{2}\right)^{2}}{16\left(128+96 A^{2}+85 A^{4}\right)}} \\
& u(t)=(A+c) \cos \omega t-(c) \cos 3 \omega t
\end{aligned}
$$

\subsection{Results and discussion of case 3}

The model of a simple mathematical pendulum equation with neglecting the friction investigated in previous section and solved analytically with NHBM. The frequency obtained with second order analytical approximation (Eq. (26)) compared with Max-Min approach, Variational Iteration Method, Energy Balance Method and Homotopy Perturbation Method in table 2 .

Fig. 4 shows the schematic of Eq. (27) which solved by NHBM and compared with time marching solution for two initial amplitudes. This figure shows the accuracy and effectiveness of this method. The stability of the system investigates by illustrating phase plane of the system in Fig. 5. Also, the effect of initial amplitude on phase plane showed in this figure. Fig. 6 demonstrates the system response behavior in presence of time and initial amplitude.

Table 2. Comparison of the frequency obtained via NHBM with other analytical solution.

\begin{tabular}{|c|c|c|c|c|c|}
\hline A & $\begin{array}{c}\text { Max-Min } \\
{[23]}\end{array}$ & $\begin{array}{c}\text { VIM } \\
{[27]}\end{array}$ & $\begin{array}{c}\text { EBM } \\
{[28]}\end{array}$ & $\begin{array}{c}\text { HPM } \\
{[28]}\end{array}$ & $\begin{array}{c}\text { Present } \\
\text { study }\end{array}$ \\
\hline 0.01 & 0.9999 & 0.9999 & 1.0000 & 1.0000 & 0.9999 \\
\hline 0.1 & 0.9993 & 0.9993 & 0.9994 & 0.9994 & 0.9993 \\
\hline 0.2 & 0.9975 & 0.9975 & 0.9975 & 0.9975 & 0.9975 \\
\hline 0.4 & 0.9900 & 0.9900 & 0.9900 & 0.9900 & 0.9900 \\
\hline 0.6 & 0.9775 & 0.9775 & 0.9774 & 0.9776 & 0.9775 \\
\hline 0.8 & 0.9600 & 0.9602 & 0.9597 & 0.9603 & 0.9601 \\
\hline 1 & 0.9377 & 0.9381 & 0.9367 & 0.9382 & 0.9378 \\
\hline 1.5 & 0.8606 & 0.8632 & 0.8550 & 0.8632 & 0.8613 \\
\hline
\end{tabular}


M. Mashinchi Joubari, R. Asghari, M. Zareian Jahromy/ TJMCS Vol. 4 No. 3 (2012) 418- 427

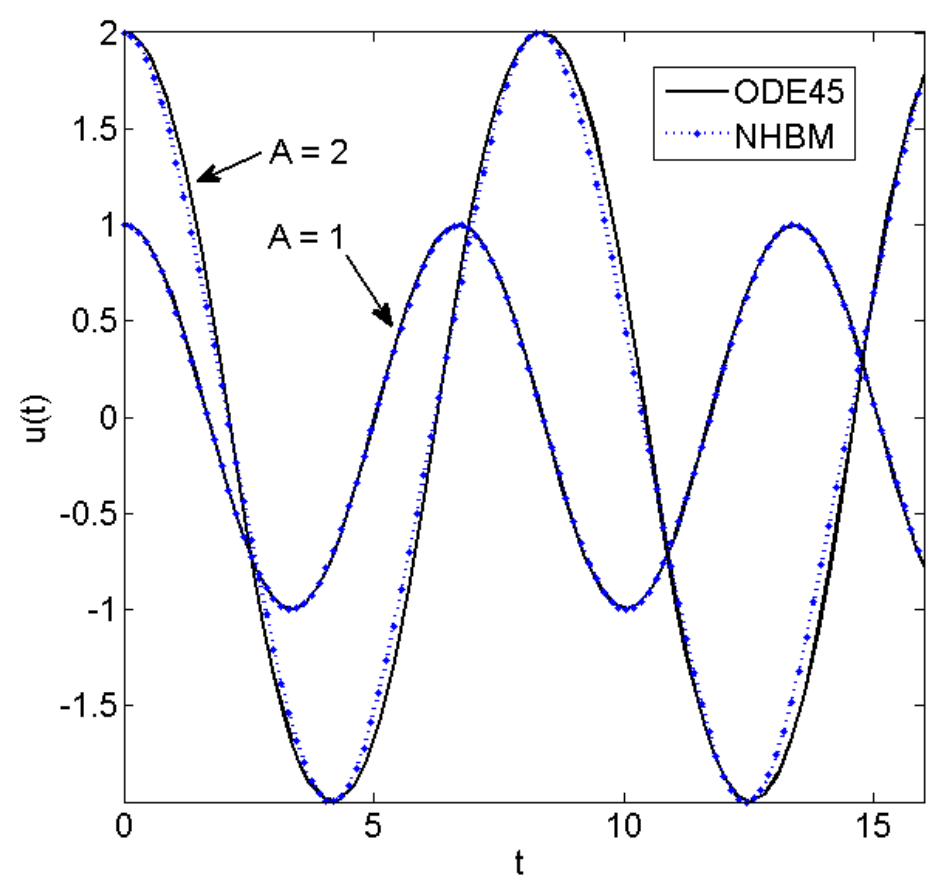

Fig. 4. Response of the system with NHBM and time marching solution for two different $A$.

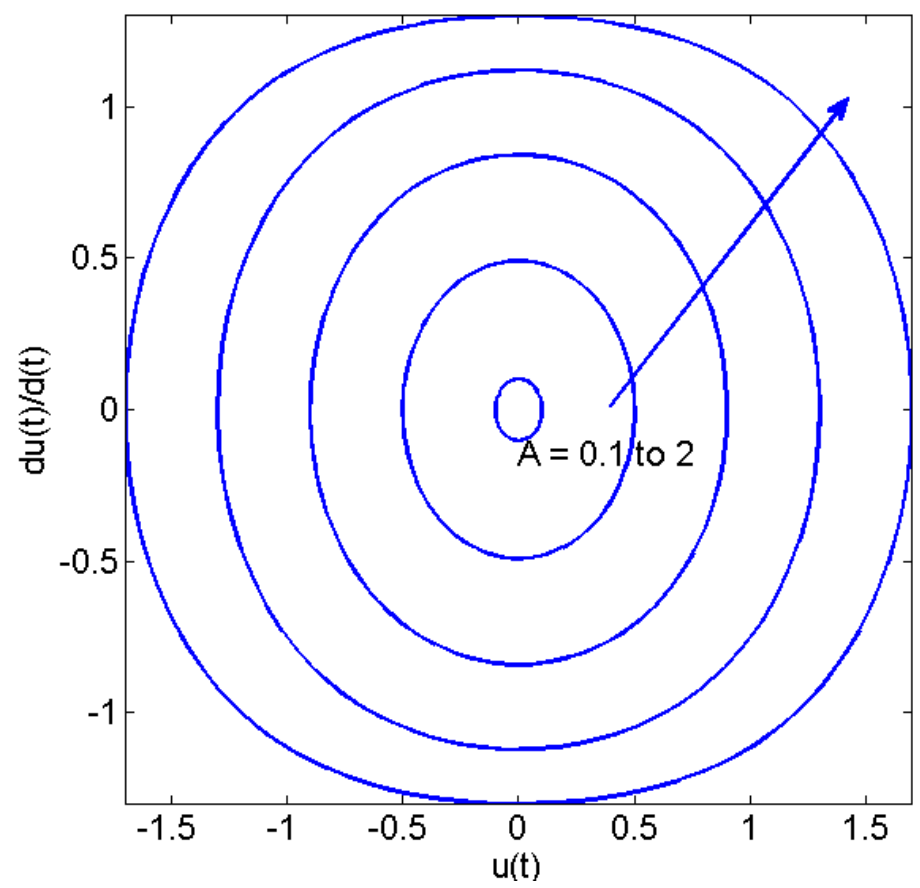

Fig. 5. Influence of changing $A$ on phase plane of the system. 


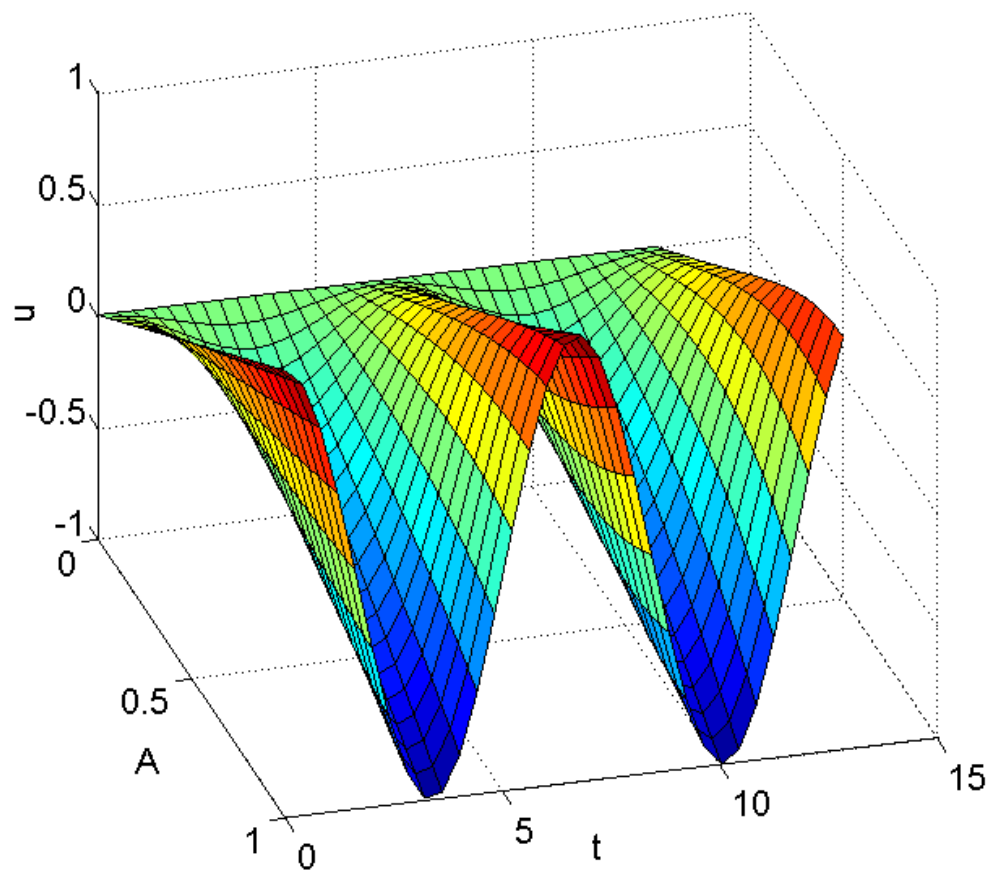

Fig. 6. Influence of initial amplitude on time histories of NHBM response.

\section{Conclusion}

In the present work, Newton Harmonic Balance Method applied to obtain analytical solution for nonlinear vibration in oscillatory systems. For this purpose, two problems with periodic behavior selected for investigating the effectiveness of this method. Results of the NHBM are compared with other analytical methods done in other literatures and time marching solutions. As indicated, the error of the studied systems is very worthless and the results confirmed the accuracy and the efficiently of the method. However, further research is needed to better understanding the effect of this method on engineering problems especially mechanical affairs.

\section{References}

[1] R.J. Yatawara, R.D. Neilson, A.D.S. Barr, Theory and experiment on establishing the stability boundaries of a one-degree-of-freedom system under two high- frequency parametric excitation inputs, Journal of Sound and Vibration. 297 (2006) 962-980.

[2] A.M. Othman, D. Watt, A.D.S. Barr, Stability boundaries of an oscillator under high frequency multi-component parametric excitation, Journal of Sound and Vibration. 112 (1987) 249-259.

[3] Junfeng Lu, An analytical approach to the Fornberg-Whitham type equations by using the variational iteration method, Computers and Mathematics with Applications. 61 (2011) 20102013.

[4] Yasir Nawaz, Variational iteration method and homotopy perturbation method for fourthorder fractional integro-differential equations, Computers and Mathematics with Applications. 61 (2011) 2330-2341.

[5] S.M. Moghimia, D.D. Ganji, H. Bararnia, M. Hosseini, M. Jalaal, Homotopy perturbation method for nonlinear MHD Jeffery-Hamel Problem, Computers and Mathematics with Applications. 61 (2011) 2213-2216. 
[6] Abdoul R. Ghotbi, H. Bararnia, G. Domairry, A. Barari, Investigation of a powerful analytical method into natural convection boundary layer flow, Commun Nonlinear Sci Numer Simulat. 14 (2009) 2222-2228.

[7] A.R. Sohouli, M. Famouri, A. Kimiaeifar, G. Domairry, Application of homotopy analysis method for natural convection of Darcian fluid about a vertical full cone embedded in pours media prescribed surface heat flux, Commun Nonlinear Sci Numer Simulat. 15 (2010) 16911699.

[8] A. Fereidoon, D.D. Ganji, H.D. Kaliji, M. Ghadimi, Analytical solution for vibration of buckled beams, International Journal of Research and Reviews in Applied Sciences. 4(3) (2010) 17-21.

[9] F. Farrokhzad, P. Mowlaee, A. Barari, A.J. Choobbasti, H.D. Kaliji, Analytical investigation of beam deformation equation using perturbation, homotopy perturbation, variational iteration and optimal homotopy asymptotic methods, Carpathian Journal of Mathematics. 27(1) (2011) 51-63.

[10] Shimin Guo, Liquan Mei, The fractional variational iteration method using He's polynomials, Physics Letters A. 375 (2011) 309-313.

[11] Jafar Biazar, Mehdi Gholami Porshokouhi, Behzad Ghanbari, Mohammad Gholami Porshokouhi, Numerical solution of functional integral equations by the variational iteration method, Journal of Computational and Applied Mathematics. 235 (2011) 2581-2585.

[12] H.D. Kaliji, A. Fereidoon, M. Ghadimi, M. Eftari, Analytical Solutions for Investigating Free Vibration of Cantilever Beams, World Applied Sciences Journal. 9 (Special Issue of Applied Math) (2010) 44-48.

[13] A. Barari, H.D. Kaliji, M. Ghadimi, G. Domairry, Non-linear vibration of EulerBernoulli beams, Latin American Journal of Solids and Structures. 8 (2011) In Press.

[14] A. Fereidoon, M. Ghadimi, H.D. Kaliji, M. Eftari, S. Alinia, Variational Iteration Method for Nonlinear Vibration of Systems with Linear and Nonlinear Stiffness, International Journal of Research and Review in Applied Siences. 5(3) (2010) 260-263.

[15] Zhao Ling, He's frequency-amplitude formulation for nonlinear oscillators with an irrational force, Computers and Mathematics with Applications. 58 (2009) 2477-2479.

[16] Ji-Huan. He, Max-min approach to nonlinear oscillators, Int. J. Nonlinear Sci. Numer. Simul. 9(2) (2008) 207-210.

[17] S.S. Ganji, A. Barari, D.D. Ganji, Approximate analysis of two-mass-spring systems and buckling of a column, Computers and Mathematics with Applications. 61 (2011) 1088-1095.

[18] Turgut. Özis, Ahmet. Yıldırım, Determination of the frequency-amplitude relation for a Duffing-harmonic oscillator by the energy balance method. Computers and Mathematics with Applications. 54 (2007) 1184-1187.

[19] A. Fereidoon, M. Ghadimi, A. Barari, H.D. Kaliji, G. Domairry, Nonlinear vibration of oscillation systems using frequency amplitude formulation, Shock and Vibration. 18 (2011) $1-10$, DOI :10.3233/SAV20100633 In Press.

[20] A. Beléndez_, D.I. Méndez, T. Beléndez, A. Hernández, M.L. Álvarez, Harmonic balance approaches to the nonlinear oscillators in which the restoring force is inversely proportional to the dependent variable, Journal of Sound and Vibration. 314 (2008) 775-782.

[21] B.S. Wu, W.P. Sun, C.W. Lim, An analytical approximate technique for a class of strongly non-linear oscillators, International Journal of Non-Linear Mechanics. 41 (2006) 766-774.

[22] S.K. Lai, C.W. Lim, B.S. Wu, C. Wang, Q.C. Zeng, X.F. He, Newton-harmonic balancing approach for accurate solutions to nonlinear cubic-quintic Duffing oscillators, Applied Mathematical Modelling. 33 (2009) 852-866. 
[23] L.B. Ibsen, A. Barari, A. Kimiaeifar, Analysis of highly nonlinear oscillation systems using He's max-min method and comparison with homotopy analysis and energy balance methods, Sadhana. 35 (2010) 1-16.

[24] J.H. He, Non-perturbative methods for strongly nonlinear problems, Dissertation.deVerlag im Internet GmbH, 2006.

[25] R.E. Mickens, Mathematical and numerical study of the Duffing-harmonic oscillator, Journal of Sound and Vibration. 244(3) (2001) 563-567.

[26] S.B. Tiwari, B.N. Rao, N.S. Swamy, K.S. Sai, H.R. Nataraja, Analytical study on a Duffing-harmonic oscillator, Journal of Sound and Vibration. 285 (2005) 1217-1222.

[27] Ji-Huan He, Variational iteration method - a kind of non-linear analytical technique: some examples, International Journal of Non-Linear Mechanics. 34 (1999) 699-708.

[28] H. Babazadeh, D.D. Ganji, and M. Akbarzade, He's energy Balance method to evaluate the effect of amplitude on the natural frequency in nonlinear vibration systems, Progress In Electromagnetics Research M. 4 (2008)143-154. 